Article

\title{
Fabrication of a P3HT-ZnO Nanowires Gas Sensor Detecting Ammonia Gas
}

\author{
Chin-Guo Kuo, Jung-Hsuan Chen *, Yi-Chieh Chao and Po-Lin Chen \\ Department of Industrial Education, National Taiwan Normal University, 162, Sec.1, Heping E. Rd., \\ Taipei 10610, Taiwan; chinguo7@yahoo.com.tw (C.-G.K.); ycchao@ntnu.edu.tw (Y.-C.C.); \\ 60670024h@ntnu.edu.tw (P.-L.C.) \\ * Correspondence: jhchen@ntnu.edu.tw; Tel.: +886-2-7734-3365
}

Received: 17 October 2017; Accepted: 20 December 2017; Published: 25 December 2017

\begin{abstract}
In this study, an organic-inorganic semiconductor gas sensor was fabricated to detect ammonia gas. An inorganic semiconductor was a zinc oxide $(\mathrm{ZnO})$ nanowire array produced by atomic layer deposition (ALD) while an organic material was a p-type semiconductor, poly(3-hexylthiophene) (P3HT). P3HT was suitable for the gas sensing application due to its high hole mobility, good stability, and good electrical conductivity. In this work, P3HT was coated on the zinc oxide nanowires by the spin coating to form an organic-inorganic heterogeneous interface of the gas sensor for detecting ammonia gas. The thicknesses of the P3HT were around $462 \mathrm{~nm}, 397 \mathrm{~nm}$, and $277 \mathrm{~nm}$ when the speeds of the spin coating were $4000 \mathrm{rpm}, 5000 \mathrm{rpm}$, and $6000 \mathrm{rpm}$, respectively. The electrical properties and sensing characteristics of the gas sensing device at room temperature were evaluated by Hall effect measurement and the sensitivity of detecting ammonia gas. The results of Hall effect measurement for the P3HT-ZnO nanowires semiconductor with $462 \mathrm{~nm}$ P3HT film showed that the carrier concentration and the mobility were $2.7 \times 10^{19} \mathrm{~cm}^{-3}$ and $24.7 \mathrm{~cm}^{2} \cdot \mathrm{V}^{-1} \cdot \mathrm{s}^{-1}$ respectively. The gas sensing device prepared by the P3HT-ZnO nanowires semiconductor had better sensitivity than the device composed of the $\mathrm{ZnO}$ film and P3HT film. Additionally, this gas sensing device could reach a maximum sensitivity around 11.58 per ppm.
\end{abstract}

Keywords: poly(3-hexylthiophene); zinc oxide nanowire; gas sensor; ammonia gas

\section{Introduction}

In past decades, gas sensors based on metal oxide semiconductors have drawn much attention for wide applications [1-5] such as environmental monitoring, industrial process control, and for the detection of the chemical or toxic substrates. Recently, the gas sensors composed of nanostructured semiconductors, such as nanowires, nanoparticles, nanorods, and nanobelts, show better sensitivities to different gases [6-9]. The sensors with nanostructures have been demonstrated to be excellent candidates for high sensitivity due to their high surface to volume ratio. However, some limitations of these sensors based on metal oxide semiconductors, like high working temperature could be seen [10].

Organic semiconductors have potential to be used as the sensing layer of the gas sensor because they have good gas sensing performance and can be used to fabricate the low cost gas sensors. High selectivity for gas and operating in the lower temperature are the most notable advantages for the organic gas sensors [11,12]. Poly(3-hexylthio-phene) (P3HT) is a widely investigated conductive conjugated polymer and exhibits a tendency to self-assemble into polycrystalline structure when casts from the solution phase [13]. P3HT is a very stable p-type semiconductor with holes as carriers and usually used in the organic thin film transistor (OTFT) sensors. A. Assadi and his coworkers [14] proposed a P3HT based field effect transistor (FET) in 1990 and found that changes in electrical properties of FET upon exposure to alumina gas were reversible. Fukuda et al. [15] showed that the regioregular P3HT thin film transistor was sensitive to $1000 \mathrm{ppm}$ of $\mathrm{N}_{2} \mathrm{O}$ gas exposure at 
$50{ }^{\circ} \mathrm{C}$. Jeong et al. [16] reported that response characteristics of P3HT based OTFT sensors exposed to ammonia gas with concentrations ranging from 10 to $100 \mathrm{ppm}$ at room temperature in normal atmosphere. Additionally, Saxena et al. [10] demonstrated that P3HT: ZnO nanowire hybrid films exhibited high sensivity, fast response, and enhanced selectivity for $\mathrm{NO}_{2}$ gas in the 0-10 ppm range at room temperature. Organic-inorganic hybrid materials exhibited good mechanical and electrical properties, and could be used in a selective gas sensor.

In the present study, an ammonia gas sensor consisting of the P3HT film and the ZnO nanowires was fabricated. P3HT film was coated on the surface of the $\mathrm{ZnO}$ nanowires by spin coating technique and then an organic-inorganic heterojunction was formed. Combining the benefits of two materials, it is believed that this structure would exhibit higher electrical properties and more sensitive performance for gas sensing. The findings of this study will provide helpful information for designing and fabricating highly sensitive gas sensors with organic-inorganic semiconductors.

\section{Materials and Methods}

An aluminum film was coated on a conductive glass of indium tin oxide (ITO) using RF magnetron sputter. Then a two-step anodization treatment was adopted to prepare the anodic aluminum oxide (AAO) template. First step of the anodization was carrying out in $0.3 \mathrm{M}$ oxalic acid solution by applying 40 volts at $0{ }^{\circ} \mathrm{C}$ for $30 \mathrm{~s}$. The as-prepared oxide layer was then removed using a mixture solution of $3 \%$ chromic acid solution $\left(\mathrm{CrO}_{3}\right)$ and $6 \%$ phosphoric acid solution $\left(\mathrm{H}_{3} \mathrm{PO}_{4}\right)$ at $60{ }^{\circ} \mathrm{C}$. Second step of the anodization was performed under the same condition as the first anodization, but anodizing time became $1.5 \mathrm{~min}$. Finally, a pore widening process was executed using $5 \%$ phosphoric acid solution. In this study, the $\mathrm{ZnO}$ nanowires were fabricated within the AAO template by the atomic layer deposition (ALD). The AAO/ITO specimen rinsing with the deionized (DI) water and acetone solution was placed in a chamber under a high vacuum of $10^{-6}$ Torr. ZnO was then deposited into the nanopores of the AAO template. It was difficult to know when the nanopore was filled with $\mathrm{ZnO}$, therefore the excess $\mathrm{ZnO}$ would become a $\mathrm{ZnO}$ film on the surface of the AAO template after the ALD process. In order to remove the extra $\mathrm{ZnO}$ film, a wet etching was performed using the hydrochloric acid $(\mathrm{HCl})$ solution. After that, the AAO template dissolved in the sodium hydroxide $(\mathrm{NaOH})$ solution and the $\mathrm{ZnO}$ nanowires with a high aspect ratio were exposed, as shown in Figure 1. For details of the procedure for the formation of the $\mathrm{ZnO}$ nanowires, refer to our previous paper [17].

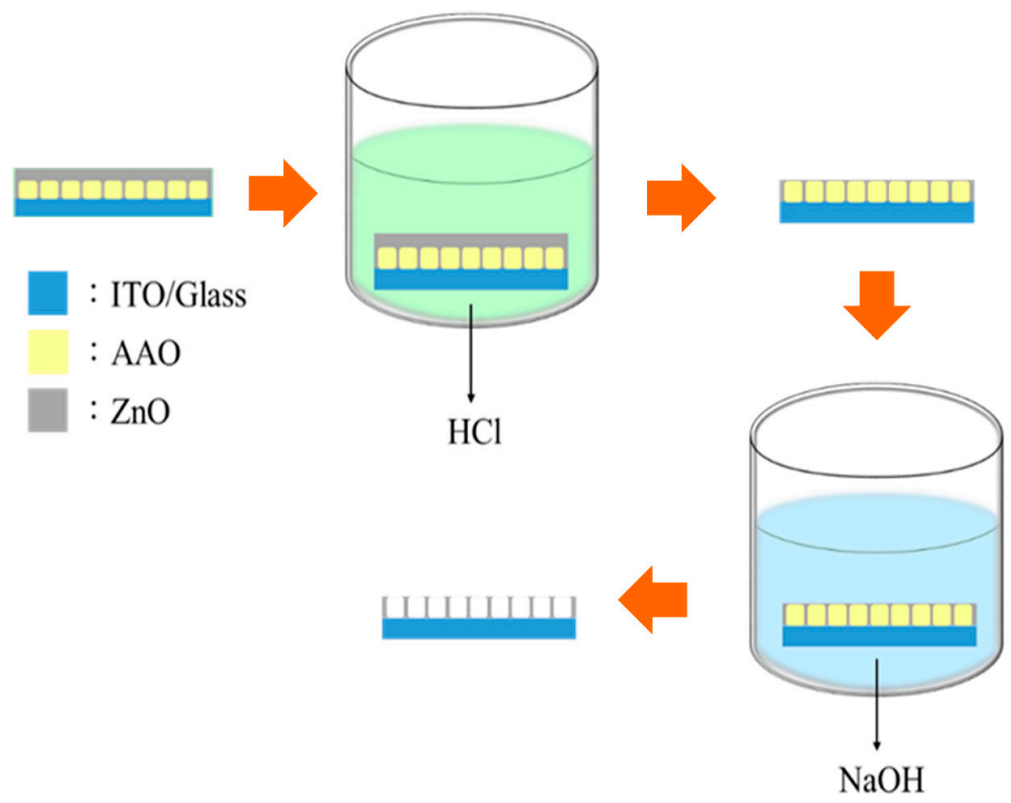

Figure 1. The process flow of removing the anodic aluminum oxide (AAO) template by the wet etching method. 
Spin coating technique was adopted to prepare a uniform P3HT film on the surface of the $\mathrm{ZnO}$ nanowires. P3HT was dissolved in an organic solvent, tetrahydrofuran (THF), and produced a $1 \mathrm{wt} . \%$ P3HT solution for spin coating. In order to obtain a smooth and well distributed P3HT film on the surface of the nanowires, the spin coating process was divided into two stages. At the first stage, the rotation speed was $500 \mathrm{rpm}$ (round per minute) for $5 \mathrm{~s}$. Then, the rotation speed was raised to various speeds of 4000, 5000, and $6000 \mathrm{rpm}$ for $30 \mathrm{~s}$ to prepare a uniform P3HT film on the surface of the $\mathrm{ZnO}$ nanowires.

The P3HT-ZnO nanowires (organic-inorganic semiconductors) gas sensor could be obtained after aluminum electrodes deposited on the surface of the P3HT film by the thermal evaporator and the schematic diagram of the sensing device was shown in Figure 2.The sensing properties of the prepared P3HT-ZnO nanowires gas sensor were measured at room temperature under various concentrations of ammonia gas and the gas detection system was illustrated in Figure 3. In this study, the morphologies of the AAO template and the $\mathrm{ZnO}$ nanowires were inspected by scanning electron microscopy (SEM) and crystalline structure of the $\mathrm{ZnO}$ nanowires was carried out using $\mathrm{X}$-ray diffraction (XRD) analysis. The carrier concentration and the mobility of the semiconductor composed of the P3HT and the ZnO nanowires were determined by Hall effect measurement.

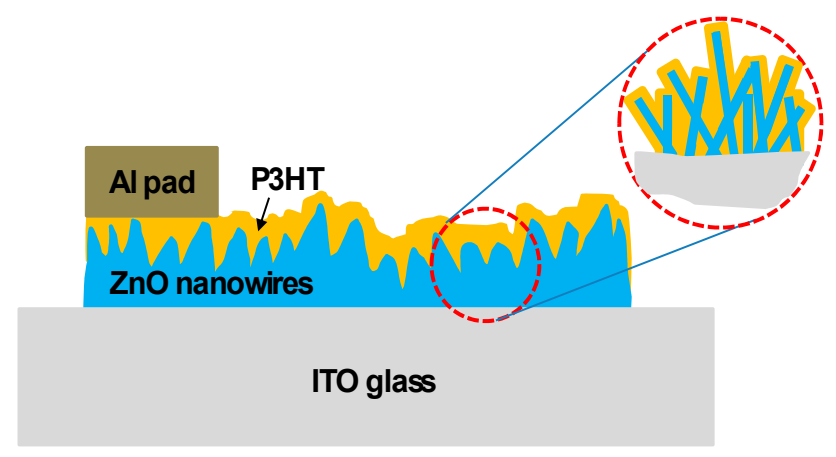

Figure 2. Schematic diagram of the sensing device.

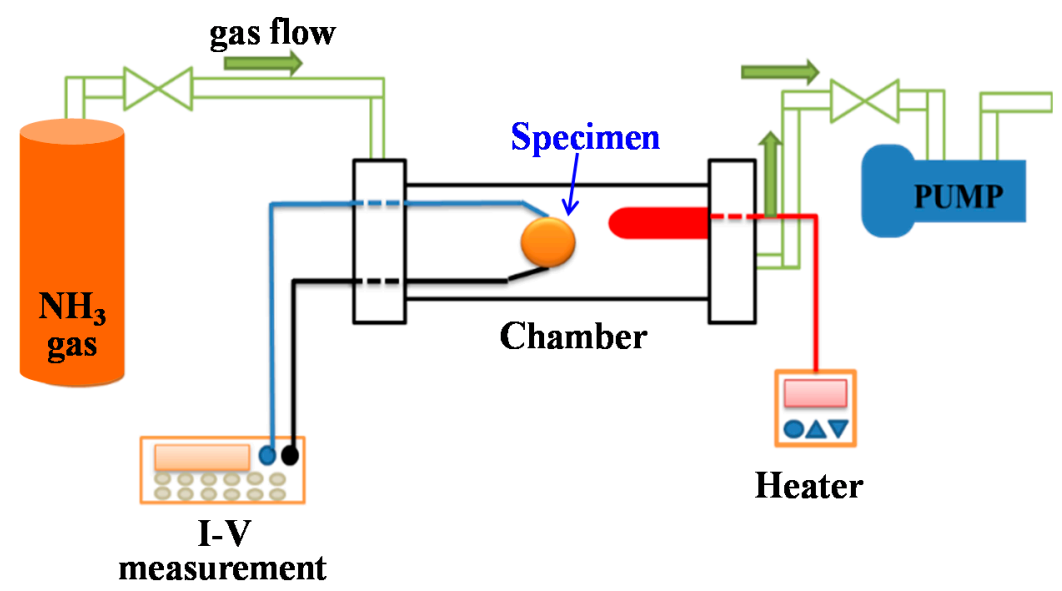

Figure 3. The equipment for gas sensing.

\section{Results and Discussion}

The AAO template is a self-assembled nanoporous film in which the pore size and the distribution are influenced by the working voltage, electrolyte compositions, and other parameters [18-21]. In the present work, the AAO template was produced on the ITO glass in $0.3 \mathrm{M}$ oxalic acid solution at $40 \mathrm{~V}$. Figure 4a showed the surface morphology of the AAO template after a pore widening process using $5 \%$ phosphoric acid solution. The straight nanopore was found through the cross-sectional view of the 
AAO template as showed in Figure $4 \mathrm{~b}$. $\mathrm{ZnO}$ was deposited into the nanopores of the AAO template by the ALD process. The $\mathrm{ZnO}$ nanowires could be obtained after the extra $\mathrm{ZnO}$ film which was capped the surface of the AAO template and the AAO template were removed using $0.1 \mathrm{M} \mathrm{HCl}$ solution for $10 \mathrm{~s}$ and $0.1 \mathrm{M} \mathrm{NaOH}$ solution for $10 \mathrm{~min}$, respectively. Figure 5 revealed that the dense $\mathrm{ZnO}$ nanowires with a high aspect ratio were produced. The crystal structures of the $\mathrm{ZnO}$ nanowires and the $\mathrm{ZnO}$ film, which were both fabricated with the ALD technique, were examined by XRD analysis. The results in Figure 6 indicated that the $\mathrm{ZnO}$ film consisted of the wurtzite structure and the zincite structure. The spectrum of the $\mathrm{ZnO}$ nanowires showed the small diffraction signals of the wurtzite structure and a board amorphous signal might come from the residues of the AAO template [22]. The small diffraction signals of wurtzite structure were contributed by the finer $\mathrm{ZnO}$ nanostructures and the confinement of the AAO template.
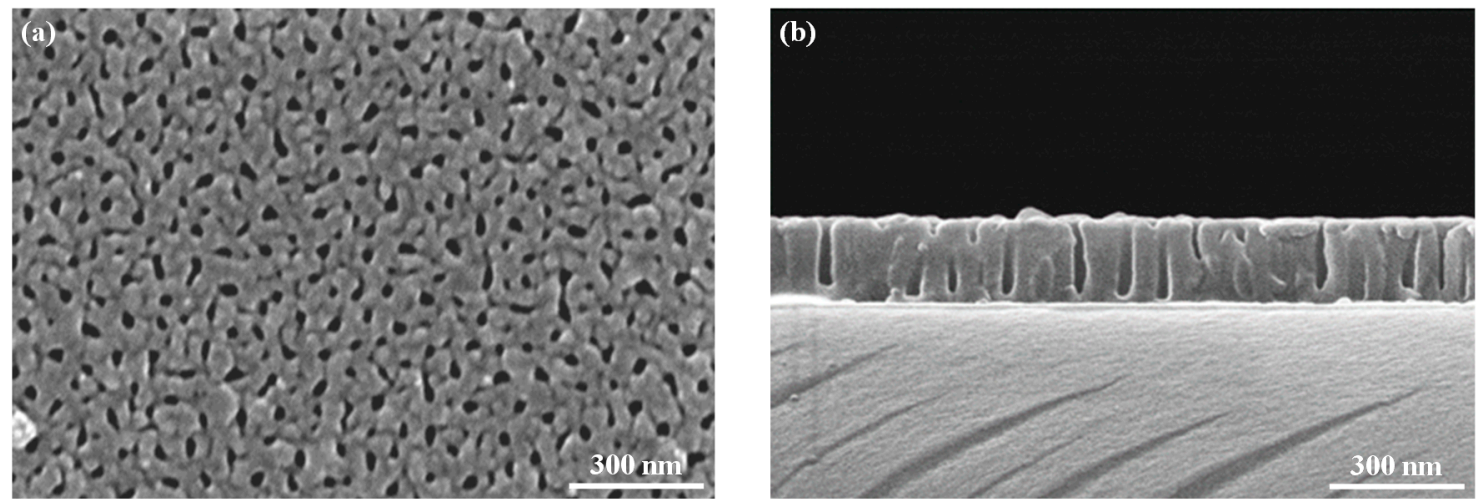

Figure 4. Scanning electron microscope (SEM) images of the AAO template: (a) top view; (b) cross-sectional view.

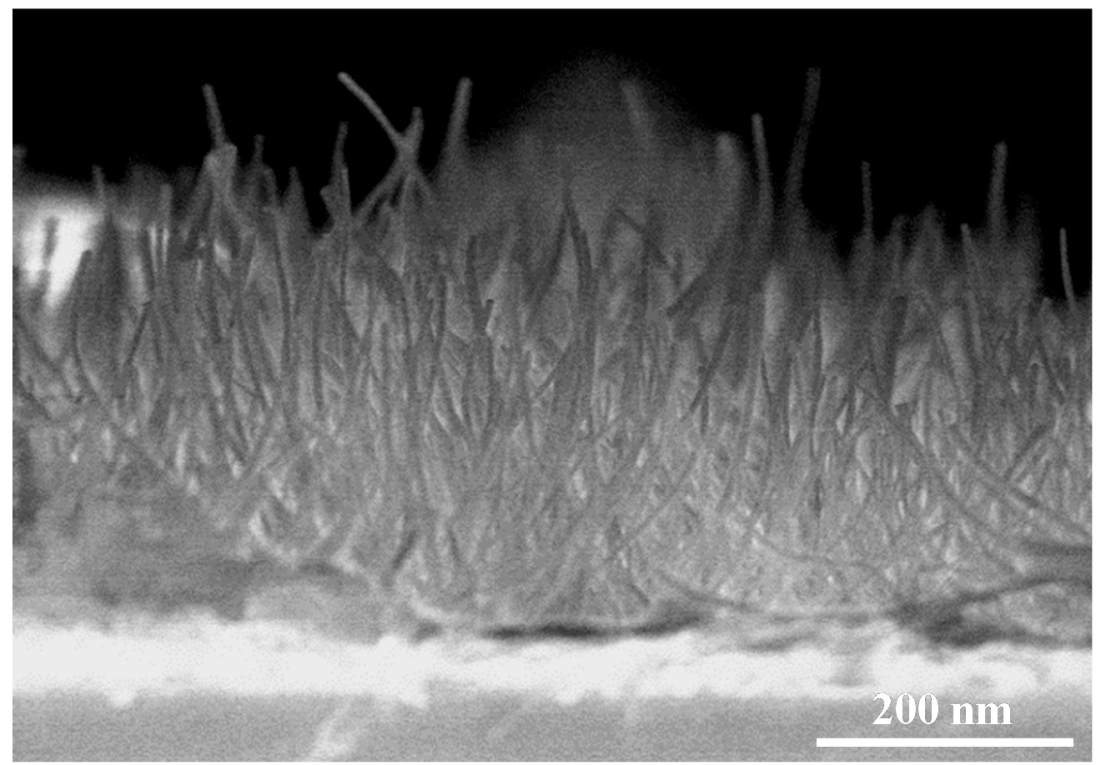

Figure 5. Zinc oxide $(\mathrm{ZnO})$ nanowires without the AAO template which was removing by immersing in $0.1 \mathrm{M}$ sodium hydroxide $(\mathrm{NaOH})$ solution for $10 \mathrm{~min}$.

In order to fabricate an ammonia gas sensor device, the sensing layer, P3HT, was coated on the as-prepared $\mathrm{ZnO}$ nanowires by the spin coating method. The thickness of the P3HT could be adjusted by varying the rotation speed. In this work, various rotation speeds, $4000 \mathrm{rpm}, 5000 \mathrm{rpm}$, and $6000 \mathrm{rpm}$ were adopted and the corresponding thickness of P3HT film were respectively around $462 \mathrm{~nm}, 397 \mathrm{~nm}$, and $277 \mathrm{~nm}$. The results of Hall effect measurement for P3HT-ZnO nanowires semiconductor with $462 \mathrm{~nm}$ P3HT film showed that the carrier concentration and the mobility were 
$2.7 \times 10^{19} \mathrm{~cm}^{-3}$ and $24.7 \mathrm{~cm}^{2} \cdot \mathrm{V}^{-1} \cdot \mathrm{s}^{-1}$. In comparison with the pure P3HT film which mobility was around $10^{-3}$ to $10^{-2} \mathrm{~cm}^{2} \cdot \mathrm{V}^{-1} \cdot \mathrm{s}^{-1}$, the significant increases of both carrier concentration and mobility of P3HT-ZnO nanowires semiconductor might be contributed from a synergetic effect of the organic and inorganic moieties. The similar phenomenon observed in $\mathrm{P} 3 \mathrm{HT}-\mathrm{SnO}_{2}$ composite semiconductor was reported by Geng and his coworkers [23].

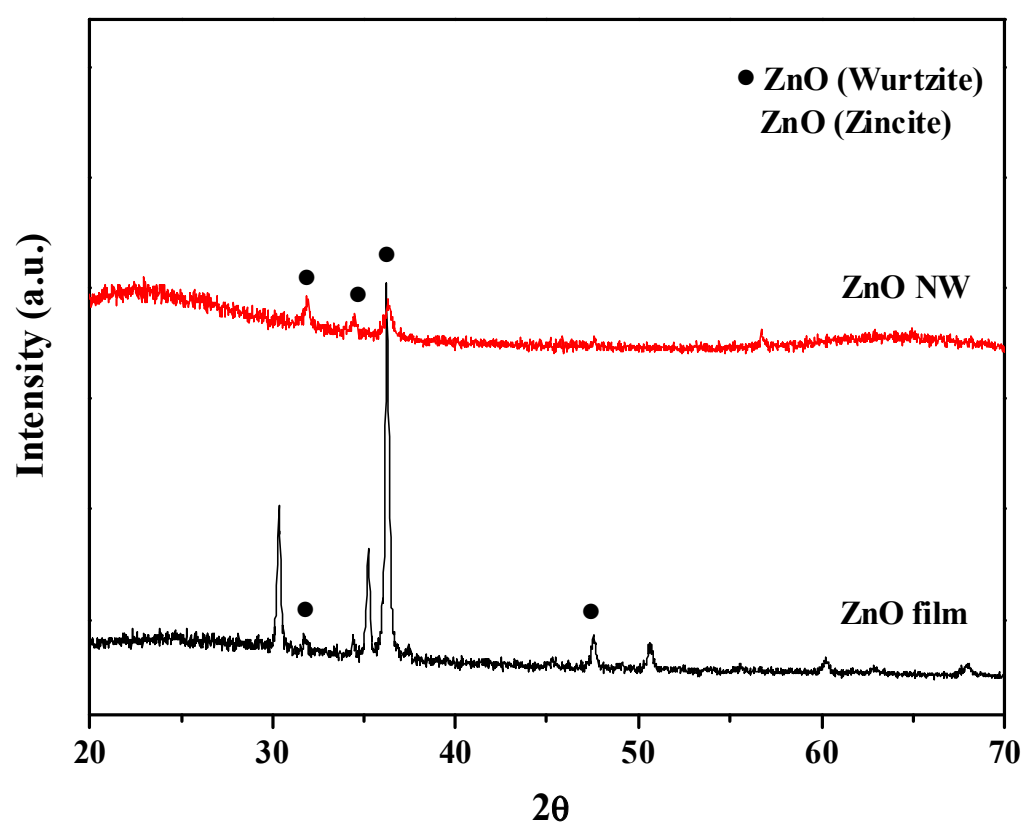

Figure 6. X-ray diffraction (XRD) results of the $\mathrm{ZnO}$ film and the $\mathrm{ZnO}$ nanowires.

The ammonia sensing properties of the device were measured by the resistance change under an ammonia gas ambient at various concentrations of 5 ppm, 1 ppm, 0.5 ppm and 0.1 ppm in this experiment. The gas response of the sensing device is defined by the ratio of the variation of the resistance change and the initial resistance, as showed in following formula.

$$
\text { Response }=\frac{\Delta R}{R_{0}} \times 100 \%=\frac{R_{g a s}-R_{0}}{R_{0}} \times 100 \%
$$

$R_{0}$ is the initial resistance. $R_{g a s}$ is the resistance of the gas sensor under the target gas ambient. Sensitivity $(S)$ of the sensing device is defined as [24]:

$$
S=\frac{R_{g a s} / R_{0}}{C_{g}}
$$

where $C_{g}$ refers to the gas concentration of the target gas.

Figure 7 showed the response of P3HT-ZnO nanowires sensors with various P3HT thicknesses to the 5 ppm ammonia gas. All three sensors showed responses to ammonia gas and the gas response of the P3HT-ZnO nanowires increased with increasing thickness of the P3HT.The sensor with $462 \mathrm{~nm}$ P3HT film produced by the rotation speed of $4000 \mathrm{rpm}$ had the best gas response to ammonia gas among the three sensors. It was supposed that the thinner P3HT could not cover the nanowires well because the length of nanowires of several hundred nanometers was observed in the SEM image. The poor surface coverage would lead to poor gas sensing performance. Figure 8 displayed the dynamic responses of the P3HT-ZnO nanowires sensor with $462 \mathrm{~nm}$ P3HT film exposing to different concentrations of ammonia gases from $0.1 \mathrm{ppm}$ to $5 \mathrm{ppm}$. Figure 9 showed the response of the P3HT-ZnO nanowires sensor with $462 \mathrm{~nm}$ P3HT film for different concentrations of ammonia gas. For comparison, the responses of the P3HT sensor and the P3HT-ZnO film sensor were also measured. 
The P3HT-ZnO nanowires sensor had the higher response to the ammonia gas in all the examined concentrations than the P3HT sensor and the P3HT-ZnO film sensor, and the maximum sensitivity was around 11.58 per ppm. Table 1 showed that the comparison of the sensitivity between the P3HT-ZnO nanowires sensor and previously reported ammonia gas sensors. The data indicated that the device fabricated in this work had the lowest detection limit and the best sensitivity among the organic sensing devices.

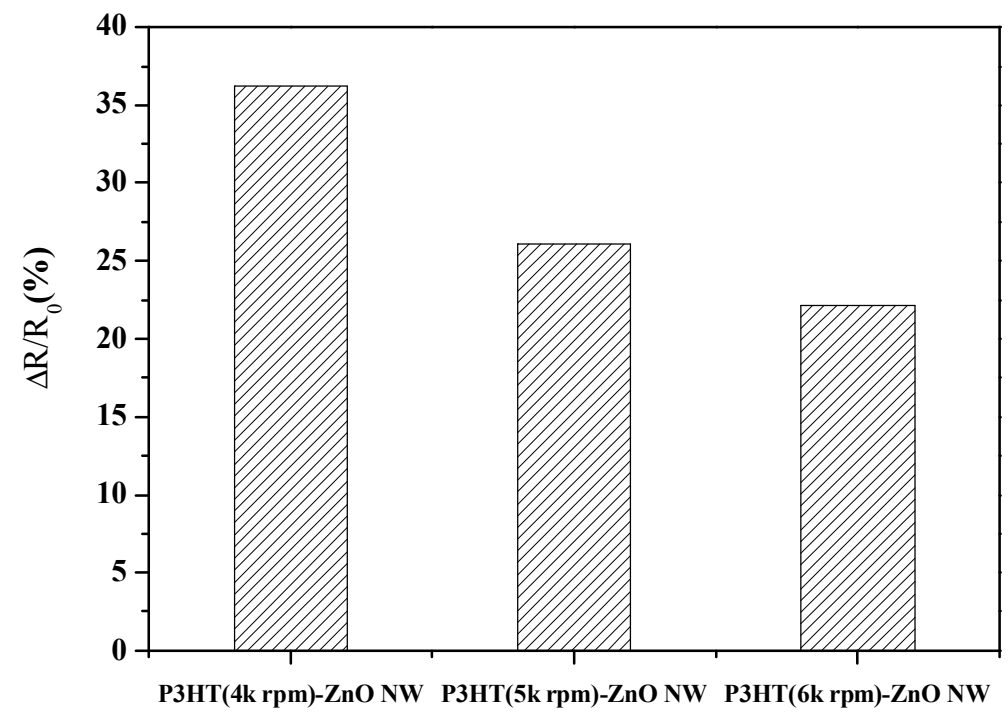

Figure 7. The responses of the poly(3-hexylthio-phene) (P3HT)-ZnO nanowires sensors with various thicknesses of the P3HT detecting 5 ppm ammonia gas.

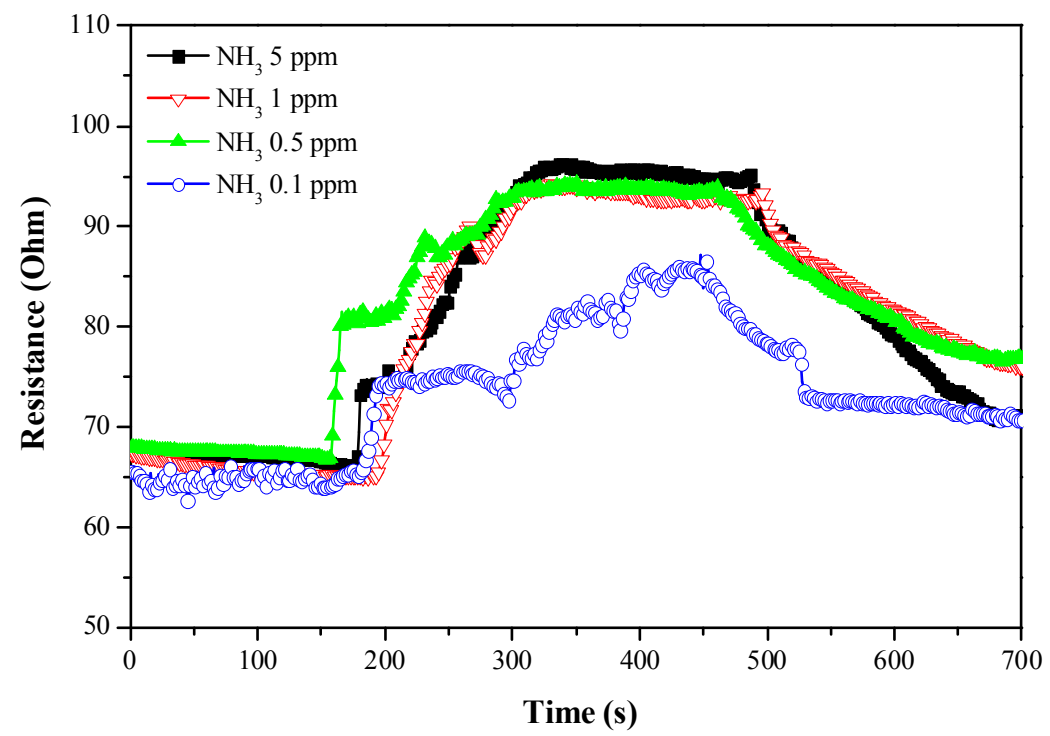

Figure 8. Dependence of resistance on time for the P3HT-ZnO naowires devices which the P3HT films were produced by the spin coating in $4000 \mathrm{rpm}$.

The P3HT-ZnO nanowires sensor could detect the low concentration of ammonia gas and the detection limit was lower than $0.1 \mathrm{ppm}$. Lower detection limit and high sensitivity were important for the ammonia gas sensor, especially for the diagnosis of liver cirrhosis [25,26]. Shimamoto and his coworkers [25] reported that breath ammonia concentrations were higher in cirrhotic patients $(\sim 0.75 \mathrm{ppm})$ than in healthy persons $(\sim 0.28 \mathrm{ppm})$. They also found that the breath ammonia concentration could correlate positively with the blood ammonia concentration. Therefore, 
the ammonia gas sensor composited of the P3HT and the $\mathrm{ZnO}$ nanowires fabricated in this study had the opportunity to be developed as a suitable device for the non-invasive diagnosis of liver diseases.

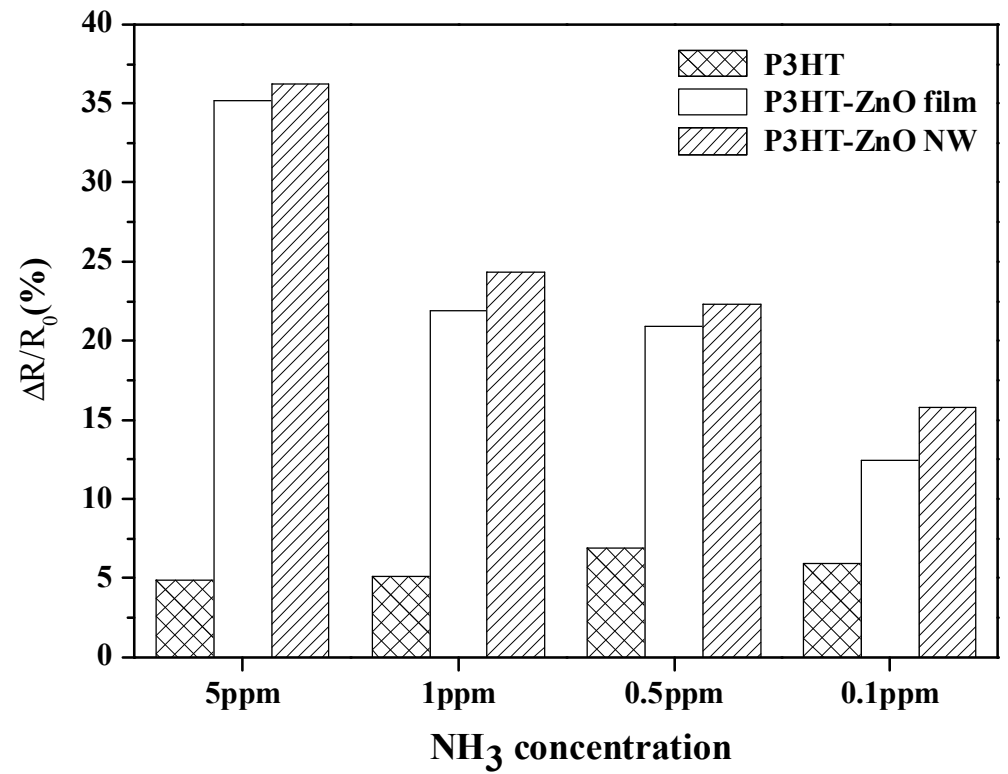

Figure 9. The comparisons of the responses of P3HT, P3HT-ZnO film and P3HT-ZnO nanowires when all P3HT films were produced by the spin coating in $4000 \mathrm{rpm}$.

Table 1. Sensing properties of the presented sensor in this work compared with other ammonia gas sensors (previous works).

\begin{tabular}{ccccc}
\hline Sensing Materials & $\begin{array}{c}\text { Working } \\
\text { Temperature }\end{array}$ & $\begin{array}{c}\text { Concentration } \\
\text { (ppm) }\end{array}$ & $\begin{array}{c}\text { Maximum Sensitivity } \\
\text { (per ppm) }\end{array}$ & Ref. \\
\hline $\mathrm{rGO}^{*}$-ZnO bilayer thin film & $\mathrm{RT}$ & 50 & 0.0206 & {$[27]$} \\
$\mathrm{MoS}_{2}-\mathrm{ZnO}$ nanocomposite & $\mathrm{RT}$ & $0.25 \sim 100$ & 0.0292 & {$[28]$} \\
$\mathrm{PPy}$ coated TiO2-ZnO & $\mathrm{RT}$ & $0.5 \sim 450$ & 0.2323 & {$[29]$} \\
$\quad$ nanofiber & $\mathrm{RT}$ & 0.4 & 25,000 & {$[30]$} \\
$\mathrm{Fe}_{2} \mathrm{O}_{3}-\mathrm{ZnO}$ nanocomposite & $\mathrm{RT}$ & $10 \sim 50$ & 0.0302 & {$[24]$} \\
$\mathrm{PANI}-\mathrm{ZnO}$ hybrid film & $\mathrm{RT}$ & $30 \sim 70$ & 0.0239 & {$[31]$} \\
$\mathrm{SnO}_{2}-\mathrm{ZnO}-\mathrm{PPy}$ multilayer & $\mathrm{RT}$ & $0.1 \sim 5$ & 11.5762 & This work \\
P3HT-ZnO nanowires & &
\end{tabular}

* rGO: reduced graphene oxide; ${ }^{* *}$ Sensitivity: $\left(R_{\text {gas }} / R_{0}\right) /$ gas concentration.

\section{Conclusions}

In this study, a gas sensor composed of the P3HT and the $\mathrm{ZnO}$ nanowires was successfully fabricated to detect ammonia gas. P3HT was coated onto the surface of the $\mathrm{ZnO}$ nanowires, which were produced by the ALD technique, using the spin coating process. The surface morphology and crystal structure of the $\mathrm{ZnO}$ nanowires produced in this work were analyzed by SEM and XRD. Experimental results showed that the $\mathrm{ZnO}$ nanowire with the wurtzite crystal structure was obtained and did not get damaged after the wet etching process. After the P3HT film was coating the surface of the $\mathrm{ZnO}$ nanowires, the Hall effect measurement revealed that the carrier concentration and the mobility were $2.7 \times 10^{19} \mathrm{~cm}^{-3}$ and $24.7 \mathrm{~cm}^{2} \cdot \mathrm{V}^{-1} \cdot \mathrm{s}^{-1}$ respectively. There were significant increases in both carrier concentration and mobility of the P3HT-ZnO nanowires semiconductor, and these might be caused by the synergetic effect of the organic and inorganic moieties. Gas sensing properties at room temperature showed that the device produced by the P3HT-ZnO nanowires in which the P3HT film was $462 \mathrm{~nm}$ in thickness had the maximum sensitivity of 11.58 per ppm, and its detection limit was lower than $0.1 \mathrm{ppm}$. 
Acknowledgments: The authors gratefully acknowledge the support of National Taiwan Normal University, through Grant No.T10607000078 and T10607000104.

Author Contributions: Kuo, C.-G. conceived and designed the experiments; Chao, Y.-C. performed the experiments; Chao, Y.-C. and Chen, J.-H. analyzed the data; Chen, J.-H. wrote the paper, and Chen, P.-L. surveyed related works.

Conflicts of Interest: The authors declared no potential conflicts of interest with respect to the research, authorship, and publication of this article.

\section{References}

1. Wang, C.; Yin, L.; Zhang, L.; Xiang, D.; Gao, R. Metal oxide gas sensors: Sensitivity and influencing factors. Sensors 2010, 10, 2088-2106. [CrossRef] [PubMed]

2. Tyagi, P.; Sharma, A.; Tomar, M.; Gupta, V. Metal oxide catalyst assisted $\mathrm{SnO}_{2}$ thin film based $\mathrm{SO}_{2}$ gas sensor. Sens. Actuators B Chem. 2016, 224, 282-289. [CrossRef]

3. Korotcenkov, G.; Brinzari, V.; Cho, B.K. Conductometric gas sensors based on metal oxides modified with gold nanoparticles: A review. Microchim. Acta 2016, 183, 1033-1054. [CrossRef]

4. Kim, H.J.; Lee, J.H. Highly sensitive and selective gas sensors using p-type oxide semiconductors: Overview. Sens. Actuators B Chem. 2014, 192, 607-627. [CrossRef]

5. Yao, M.S.; Tang, W.X.; Wang, G.E.; Nath, B.; Xu, G. MOF thin film-coated metal oxide nanowire array: Significantly improved chemiresistor sensor performance. Adv. Mater. 2016, 28, 5229-5234. [CrossRef] [PubMed]

6. Kuo, C.G.; Huang, C.W.; Chen, J.H.; Li, Y.H. Fabrication of a miniature zinc aluminum oxide nanowire array gas sensor and application for environmental monitoring. Int. J. Photoenergy 2014, 2014, 515268. [CrossRef]

7. Kuo, C.G.; Huang, J.J.; Chen, J.H.; Zeng, R.J. Fabrication of high array zinc-indium oxide nanowires and a nanowire gas sensor. Sens. Mater. 2017, 29, 533-538.

8. Xia, Y.; Wang, J.; Xu, J.L.; Li, X.; Xie, D.; Xiang, L.; Komarneni, S. Confined formation of ultrathin ZnO nanorods/reduced graphene oxide mesoporous nanocomposites for high-performance room-temperature $\mathrm{NO}_{2}$ sensors. ACS Appl. Mater. Interfances 2016, 8, 35454-35463. [CrossRef] [PubMed]

9. Kang, K.; Yang, D.; Park, J.; Kim, S.; Cho, I.; Yang, H.H.; Cho, M.; Mousavi, S.; Choi, K.H.; Park, I. Micropatterning of metal oxide nanofibers by electrohydrodynamic (EHD) printing towards highly integrated and multiplexed gas sensor applications. Sens. Actuators B Chem. 2017, 250, 574-583. [CrossRef]

10. Saxena, V.; Aswal, D.; Kaur, M.; Koiry, S.; Gupta, S.; Yakhmi, J. Enhanced $\mathrm{NO}_{2}$ selectivity of hybrid poly(3-hexylthiophene): ZnO-nanowire thin films. Appl. Phys. Lett. 2007, 90, 043516. [CrossRef]

11. Jeong, S.H.; Lee, J.Y.; Lim, B.; Lee, J.; Noh, Y.Y. Diketopyrrolopyrrole-based conjugated polymer for printed organic field-effect transistors and gas sensors. Dyes Pigment. 2017, 140, 244-249. [CrossRef]

12. Jiang, Y.; Huang, W.; Zhuang, X.; Tang, Y.; Yu, J. Thickness modulation on semiconductor towards high performance gas sensors based on organic thin film transistors. Mater. Sci. Eng. B 2017, 226, 107-113. [CrossRef]

13. Chu, P.H.; Wang, G.; Fu, B.; Choi, D.; Park, J.O.; Srinivasarao, M.; Reichmanis, E. Synergistic effect of regioregular and regiorandom poly(3-hexylthiophene) blends for high performance flexible organic field effect transistors. Adv. Electron. Mater. 2016, 2, 1500384. [CrossRef]

14. Assadi, A.; Gustafsson, G.; Willander, M.; Svensson, C.; Inganäs, O. Determination of field-effect mobility of poly(3-hexylthiophene) upon exposure to $\mathrm{NH}_{3}$ gas. Synthetic Met. 1990, 37, 123-130. [CrossRef]

15. Fukuda, H.; Ise, M.; Kogure, T.; Takano, N. Gas sensors based on poly-3-hexylthiophene thin-film transistors. Thin Solid Films 2004, 464, 441-444. [CrossRef]

16. Jeong, J.W.; Lee, Y.D.; Kim, Y.M.; Park, Y.W.; Choi, J.H.; Park, T.H. The response characteristics of a gas sensor based on poly-3-hexylithiophene thin-film transistors. Sens. Actuators B Chem. 2010, 146, 40-45. [CrossRef]

17. Hsu, W.F.; Kuo, C.G.; Chao, Y.C.; Lee, J.F.; Yang, C.F.; Juang, F.R. Growth of ZnO nano-wire arrays using AAO template and atomic-layer deposition method. In Proceedings of the International Conference on Applied System Innovation (ICASI), Okinawa, Japan, 26-30 May 2016.

18. Chu, S.Z.; Wada, K.; Inoue, S.; Isogai, M.; Yasumori, A. Fabrication of ideally ordered nanoporous alumina films and integrated alumina nanotubule arrays by high-field anodization. Adv. Mater. 2005, 17, 2115-2119. [CrossRef] 
19. Roslyakov, I.V.; Koshkodaev, D.S.; Eliseev, A.A.; Hermida-Merino, D.; Petukhov, A.V.; Napolskii, K.S. Crystallography-induced correlations in pore ordering of anodic alumina films. J. Phys. Chem. C 2016, 120, 19698-19704. [CrossRef]

20. Napolskii, K.S.; Roslyakov, I.V.; Romanchuk, A.Y.; Kapitanova, O.O.; Mankevich, A.S.; Lebedev, V.A.; Eliseev, A.A. Origin of long-range orientational pore ordering in anodic films on aluminium. J. Mater. Chem. 2012, 22, 11922-11926. [CrossRef]

21. Pashchanka, M.; Schneider, J.J. Self-ordering regimes of porous anodic alumina layers formed in highly diluted sulfuric acid electrolytes. J. Phys. Chem. C 2016, 120, 14590-14596. [CrossRef]

22. Nayar, P.; Khanna, A.; Kabiraj, D.; Abhilash, S.R.; Beake, B.D.; Losset, Y.; Chen, B. Structural, optical and mechanical properties of amorphous and crystalline alumina thin films. Thin Solid Films 2014, 568, $19-24$. [CrossRef]

23. Geng, Y.; Zhao, T.; Lian, G.; Cui, X.; Liu, Y.; Liu, J.; Wang, Q.; Cui, D. A positive synergetic effect observed in the P3HT-SnO 2 composite semiconductor: The striking increase of carrier mobility. RSC Adv. 2016, 6, 2387-2393. [CrossRef]

24. Zhu, G.; Zhang, Q.; Xie, G.; Su, Y.; Zhao, K.; Du, H.; Jiang, Y. Gas sensors based on polyaniline/zinc oxide hybrid film for ammonia detection at room temperature. Chem. Phys. Lett. 2016, 665, 147-152. [CrossRef]

25. Shimamoto, C.; Hirata, I.; Katsu, K. Breath and blood ammonia in liver cirrhosis. Hepato Gastroenterol. 2000, 47, 443-445.

26. Zan, H.W.; Li, C.H.; Yeh, C.C.; Dai, M.Z.; Meng, H.F.; Tsai, C.C. Room-temperature-operated sensitive hybrid gas sensor based on amorphous indium gallium zinc oxide thin-film transistors. Appl. Phys. Lett. 2011, 98, 253503. [CrossRef]

27. Tai, H.; Yuan, Z.; Zheng, W.; Ye, Z.; Liu, C.; Du, X. ZnO nanoparticles/reduced graphene oxide bilayer thin films for improved $\mathrm{NH}_{3}$-sensing performances at room temperature. Nanoscale Res. Lett. 2016, 11, 130. [CrossRef] [PubMed]

28. Zhang, D.; Jiang, C.; Sun, Y.E. Room-temperature high-performance ammonia gas sensor based on layer-by-layer self-assembled molybdenum disulfide/zinc oxide nanocomposite film. J. Alloys Compd. 2017, 698, 476-483. [CrossRef]

29. Wang, Y.; Jia, W.; Strout, T.; Schempf, A.; Zhang, H.; Li, B.; Cui, J.; Lei, Y. Ammonia gas sensor using polypyrrole-coated $\mathrm{TiO}_{2} / \mathrm{ZnO}$ nanofibers. Electroanalysis 2009, 21, 1432-1438. [CrossRef]

30. Tang, H.; Yan, M.; Zhang, H.; Li, S.; Ma, X.; Wang, M.; Yang, D. A selective $\mathrm{NH}_{3}$ gas sensor based on $\mathrm{Fe}_{2} \mathrm{O}_{3}-\mathrm{ZnO}$ nanocomposites at room temperature. Sens. Actuators B Chem. 2006, 114, 910-915. [CrossRef]

31. Lamdhade, G.T.; Raulkar, K.B.; Yawale, S.S.; Yawale, S.P. Fabrication of multilayer $\mathrm{SnO}_{2}-\mathrm{ZnO}-\mathrm{PPy}$ sensor for ammonia gas detection. Indian J. Phys. 2015, 89, 1025-1030. [CrossRef] 